\title{
UN ARTE MÁGICO DE EVOCACIÓN: LA MÚSICA NUEVA SEGÚN MANUEL DE FALLA
}

\author{
Teresa Cascudo \\ Universidad de La Rioja'
}

RESUMEN: Partiendo de la relectura de los escritos de Manuel de Falla, este artículo contextualiza su idea de composición musical moderna como acto creativo de carácter psicofísico y, en particular, la relación que puede establecerse entre los conceptos de evocación utilizado por el compositor, e impresión. Toma como referencia los ensayos de Émile Littré, Hippolyte Taine y Henri Bergson.

Palabras clave: Estética musical, evocación, impresión, Manuel de Falla, Hippolite Taine.

\section{A MAGICAL ART OF EVOCATION: NEW MUSIC ACCORDING TO MANUEL DE FALLA}

ABSTRACT: This article studies the definition of modern musical composition given by Manuel de Falla in his writings. It points out the importance of evocation, a term frequently used by the composer, and searches for its meaning in the

1. La preparación de este artículo fue posible gracias a una ayuda complementaria del programa de movilidad José Castillejo del Ministerio de Educación (JC 2009-0020), que la autora disfrutó como research fellow en el Institute of Musical Research de la Universidad de Londres, y al proyecto de I+D financiado por la Comunidad Autónoma de La Rioja "La crítica musical como fuente para la historia intelectual: la conformación del concepto de 'música moderna' en fuentes hemerográficas españolas entre 1915 y 1959" (IMPULSA 2007/01). Fue originalmente presentado como parte de la comunicación "Manuel de Falla's Psyché (1924), music as the magic art of evocation" en el Congreso Internacional "Revisiting the past, recasting the present: The reception of Greek Antiquity in Music, 19th century to the present", organizado en Atenas por el Hellenic Music Centre y la Fundación Cacoyannis en julio de 2011. 
context of the psycophysical aesthetics proposed by Émile Littré, Hyppolite Taine and Henri Bergson.

Keywords: Musical aesthetics, evocation, impression, Manuel de Falla, Hyppolite Taine.

A su regreso de París, el estreno madrileño de las Siete canciones españolas y La Vida Breve y la primera audición absoluta de Noches en los Jardines de España, El Amor Brujo y El corregidor y la molinera transformaron a Manuel de Falla en la referencia de la "música nueva" en su país natal². Todo esto ocurrió entre 1914 y 1919, años de intensa actividad que también contempló la divulgación musical a través de conferencias y prensa. Este origen periodístico o divulgativo condiciona el estilo de esos textos, despojados del desarrollo argumentativo propio de los ensayos académicos. Sin embargo, juntamente con la versión escrita de la semblanza de Claude Debussy, publicada en La Revue Musicale en 1920, la de Felipe Pedrell, que salió en la Revue Musicale en 1923, y el ensayo que escribió en 1933 por motivo del cincuentenario del fallecimiento de Richard Wagner, no dejan de ser una fuente importante para entender mejor las coordenadas estéticas en las que Falla se movía en esos años ${ }^{3}$.

En este artículo, me propongo, en primer lugar, releer estos escritos con el objetivo de definir, con las palabras del propio Falla, qué debía ser la música moderna. Propongo en primer lugar una definición que parte de la formulación citada en el título de este artículo: "un arte mágico de evocación" ${ }^{4}$. Intentaré

2. V. Elena Torres Clemente, Manuel de Falla, Málaga, Arguval, 2009.

3. V. Manuel de Falla, "Enrique Granados. Evocación de su obra", Revista Musical Hispanoamericana, Madrid, abril de 1916; "El gran músico de nuestro tiempo: Igor Stravinsky", La Tribuna, Madrid, 5 de junio de 1916; "La música francesa contemporánea". Prólogo al libro de Jean-Aubry, Revista Musical Hispanoamericana, Madrid, julio de 1916; "Introducción a la música nueva", Revista Musical Hispanomericana, Madrid, diciembre de 1916; "Prólogo a la Enciclopedia abreviada de música, de Joaquín Turina", Madrid, abril de 1917; "Claude Debussy y España". La Revue Musicale, París, diciembre de 1920; "Felipe Pedrell", Revue Musicale, París, febrero de 1923; "Falla y el romanticismo", Carta a Darío Pérez, octubre de 1929; "Notas sobre Ricardo Wagner en el cincuentenario de su muerte", Cruz y Raya, Madrid, septiembre de 1933. Fueron reunidos y editados por Federico Sopeña en los años 50, Manuel de Falla, Escritos sobre música y músicos, Madrid, Austral, 5ae ed., 2003, por donde citamos.

4. En general, en lo que se refiere al concepto de evocación y a su uso por parte de Falla, no se ha abordado de forma específica hasta ahora, a pesar de que aparece y reaparece, implícita y explícitamente, en una parte significativa de los estudios sobre la obra y el pensamiento del autor. Esto podría ser debido a motivos de carácter historiográfico y, por ende, ideológico. Por un lado, es evidente en la bibliografía falliana el protagonismo absoluto de la cuestión del llamado "nacionalismo esencial". Por otro lado, esta preeminencia parece haber dificultado la evaluación de su relación con las corrientes modernistas internacionales, reducidas, en su caso, al impresionismo y al simbolismo entendidos como movimientos distintos e, incluso, estancos y 
seguidamente reencuadrarlos mediante la referencia a tres autores que, durante la segunda mitad del siglo XIX, se movieron en la frontera de la psicología y la estética: Émile Littré, Hippolyte Adolphe Taine y Henri Bergson. Todos ellos tuvieron un papel fundamental en el establecimiento de la psicología como base de la estética moderna y, en particular, los dos primeros, en lo que se refiere a los movimientos impresionista y simbolista ${ }^{5}$.

Advierto que este artículo no toma en consideración sus implicaciones epistemológicas y experimentales, sino que, más bien, parte de la premisa de que la difusión de la literatura científica e, incluso en ocasiones, la mala ciencia pueden servir de base para creencias fructíferas en el ámbito artístico ${ }^{6}$. Por un lado, como escribió Ortega y Gasset, "fijar el inventario de las cosas con que se cuenta [todo aquello con que contamos y en que, de puro contar con ello, no pensamos], sería, de verdad, construir la historia, esclarecer la vida desde su subsuelo"7. Por otro lado, una reaproximación de este tipo a los escritos de un compositor reafirma la importancia de la estética musical, entendida en un sentido amplio, en cualquier investigación que pretenda explicar o describir un objeto musical, tanto en la perspectiva del proceso creativo como en el de su percepción ${ }^{8}$.

opuestos. En lo que se refiere al primero, predomina claramente la identificación del impresionismo falliano con determinados "medios de expresión" y no con cuestiones estéticas. V., como ejemplo relativamente reciente, Henri Gonnard, "L'Impressionisme, Manuel de Falla et Debussy", en Gemma Pérez Zalduondo y María Isabel Cabrera García (eds.), Cruces de caminos. Intercambios musicales y artísticos en la Europa de la primera mitad del siglo XX, Granada, Universidad de Granada, 2010, pp. 151-165. En lo que se refiere al segundo, donde se puede encuadrar la cuestión de la evocación, suele predominar la mera constatación de que la música de Falla no pretendía "imitar", sino conectar, de nuevo, diferentes "esencias" y establecer diferentes tipos de "analogías". No es éste el lugar para discutir en profundidad estas cuestiones, que, además, ya están siendo analizadas con el rigor que merecen. V., por ejemplo, respecto de la cuestión del "nacionalismo esencial", Elena Torres Clemente, "El nacionalismo de las esencias: ¿una categoría estética o ética?", en Pilar Ramos (ed.), Discursos y prácticas musicales nacionalistas (1900-1970), Logroño, Universidad de La Rioja, Servicio de Publicaciones, 2012, pp. 27 51. V., además, a propósito de la estética musical de Falla, Antonio Narejos, "La estética musical de Manuel de Falla", Tesis doctoral inédita, Universidad de Murcia, 2004.

5. Cf. Richard Shiff, Cézanne y el fin del impresionismo. Estudio de la teoría, la técnica y la valoración crítica del arte moderno, Madrid, Antonio Machado Libros-La balsa de la Medusa, 2002 (la primera edición en inglés es de 1984). El libro de Schiff, aún estando centrado en las artes plásticas, establece un contexto que nos parece, en muchos aspectos, muy adecuado para entender el pensamiento de Falla.

6. Cf. David. L. Montgomery, "The Myth of Organicism: From Bad Science to Great Art", The Musical Quarterly, 76, 1, 1992, pp. 17-66.

7. José Ortega y Gasset, "Creer y pensar", primer capítulo de Ideas y Creencias, en Obras completas, Tomo V., Madrid, Taurus, 2006, p. 665.

8. Cf. Alessandro Arbo, "Pertinences de l'esthétique musicale", en id. (ed.), Perspectives de l'esthétique musicale. Entre théorie et histoire, Paris, L'Harmattan, 2007, pp. 57-73. 


\section{Falla y la evocación}

Falla, siguiendo muy seguramente el magisterio de Debussy ${ }^{9}$, destacó sobre cualquier otra consideración, la importancia de la evocación ${ }^{10}$. Lo hizo a propósito de todos los compositores modernos en la conferencia "Introducción a la música nueva", publicada en diciembre de 1916 en la Revista Musical. Criticando el reduccionismo que suponía identificar la "música nueva" con el uso de disonancias, fue categórico: "No me cansaré de repetir que los procedimientos armónicos, por sí solos, no constituyen en manera alguna el distintivo característico de la nueva música; el espíritu nuevo reside, más que en ninguna otra cosa, en los tres elementos fundamentales de la música: el ritmo, la modalidad y las formas melódicas, fuentes al servicio de la evocación"11. En especial, en el mismo artículo, Debussy se presenta como el precursor "de un arte sonoro esencialmente nuevo, y cuyo espíritu, al modificarse según los diversos caracteres personales y aun nacionales de aquellos artistas que han seguido el camino por él abierto, ha producido obras de tal fuerza de expresión y evocación, de tal variedad de sentimientos, que jamás se hubiesen podido presentir"12. Más aún, en su opinión, todos los compositores modernos compartían la misma aspiración:

La de producir la más intensa emoción por medio de nuevas formas melódicas y modales; de nuevas combinaciones sonoras armónicas y contrapuntísticas, de ritmos obsesionantes que obedecen al espíritu primitivo de la música, que no fue otro que el actual y el que siempre debiera haber conservado; un arte mágico de evocación de sentimientos, de seres y aún de lugares por medio del ritmo y de la sonoridad ${ }^{13}$.

Todavía, por orden cronológico, Falla refirió la evocación en lo referente a la obra de los siguientes músicos: Granados y Stravinsky en 1916; Debussy en 1920; y Pedrell en 1923. El artículo sobre el primero es una especie de obituario que se presenta como "evocación" provocada por la ejecución al piano de sus obras, hasta el punto de que Falla dice percibir el "alma" de Granados en las vibraciones de las cuerdas del instrumento. En su música, "que tantas veces

9. Sobre la relación de Falla con Debussy, v. Yvan Nommick, "La présence de Debussy dans la vie et l'œuvre de Manuel de Falla. Essai d'interprétation", Cahiers Debussy, 30, 2006, pp. 27-83.

10. A propósito del uso en los escritos de Debussy del término "evocación", v. Sonsoles Hernández Barbosa, "Plus loin que la musique: evocaciones plásticas en el pensamiento de Debussy", Quintana, 8, 2009, pp. 135-145. La autora, no obstante, no llega a explicar en ningún momento el significado del término, si bien alude a su relación con la influencia de Mallarmé sobre el compositor. A este propósito, v. Anne Bourgain-Wattiau, Mallarmé ou la création au bord du gouffre. Entre littérature et psychanalyse, Paris, Éditions L'Harmattan, 1996.

11. Manuel de Falla, "Introducción a la música nueva", en Escritos sobre música y músicos, op. cit., p. 37.

12. Ibídem, p. 38.

13. Ibídem, pp. 41-42. 
ha evocado seres y cosas de tiempos pretéritos"14, y en sus ejecuciones de pianísticas, Falla elogia, póstumamente, determinados "giros melódicos [...] evocadores, como si expresaran visiones interiores del artista..." ${ }^{\prime 15}$. En lo que se refiere a Stravinsky, su "sinceridad" se derivaba de su talento para hacer uso de "medios de expresión absolutamente distintos y que sólo obedecen a lo que en música pretende evocar o exaltar"16. De la producción de Pedrell posterior a Los Pirineos, destacó tres "cualidades primordiales: personalidad en los medios de expresión, serena fuerza emotiva y raro poder evocativo" ${ }^{17}$.

Me detendré finalmente en el artículo que escribió en homenaje a Debussy, publicado en la Revue Musicale en 1920. Como se sabe, ya que se trata de uno de los textos fallianos más conocidos, celebra la figura del maestro francés elogiando su talento para escribir música que podía ser calificada como "española". La principal característica de esa música, y su principal valor, reside, siempre según Falla, en su poder evocativo. Así, "en la Soirée dans Grenade todos los elementos musicales colaboran a un solo fin: la evocación. Se podría decir que esta música, con relación a lo que la ha inspirado, nos hace el efecto de imágenes reflejadas al claro de luna sobre el agua limpia de las albercas que Ilenan la Alhambra"18. La misma cualidad evocativa se ofrece en Les parfums de la nuit y en La Puerta del Vino. Ambas están "estrechamente ligadas" a la Soirée dans Grenade "por un común elemento rítmico, el de la habanera (que hasta cierto punto no es otra cosa sino el tango andaluz), de la que Debussy quería servirse para expresar el canto nostálgico de las tardes y de las noches andaluzas." Añade Falla seguidamente: "Digo de las tardes porque lo que el músico ha querido evocar en La Puerta del Vino es la hora calma y luminosa de la siesta en Granada"19. Estas mismas ideas son ampliadas en el mismo ensayo a propósito de Iberia:

Los ecos de los pueblos, en una especie de sevillanas -el tema generador de la obra-, parecen flotar sobre una clara atmósfera de luz centelleante; la embriagadora magia de las noches andaluzas, la alegría de un pueblo que camina danzando a los festivos acordes de una banda de guitarras y de bandurrias..., todo, todo esto burbujea en el aire, aproximándose, alejándose, y nuestra imaginación, despierta incesantemente, se queda des-

14. Manuel de Falla, "Enrique Granados. Evocación de su obra", en Escritos sobre música y músicos, op. cit., p. 25.

15. Ibídem, p. 26.

16. Manuel de Falla, "El gran músico de nuestro tiempo: Igor Stravinsky", en Escritos sobre música y músicos, op. cit., p. 30.

17. Manuel de Falla, "Felipe Pedrell", en Escritos sobre música y músicos, op. cit., p. 89.

18. Manuel de Falla, "Claude Debussy y España" en Escritos sobre música y músicos, op. cit., pp. 74-75.

19. Ibídem, p. 75. 
lumbrada por las fuertes virtudes de una música intensamente expresiva y ricamente matizada ${ }^{20}$.

Este poder de evocación, no obstante, no era para Falla exclusivo de la "música nueva". Según el compositor, podía ser detectado en épocas anteriores, estando claramente separada de los medios de expresión que las pudieran caracterizar. Esto se deduce de la opinión que le merecía a Falla el romanticismo, y lo que tenía de "ilimitación, de fórmulas de engañosa profundidad, de egoísmo, de exasperación dramática..., nada más contrario a mis simpatías. En cambio, cuanto el romanticismo revela de fuerza evocadora y de lírica expansión (siempre que haya sido expresado de modo simple y natural, y sin mezcla de orgullosas intenciones) me inspira altísima simpatía"21.

Los principales medios de expresión destacados como siendo los propios de la "música nueva" aparecen enumerados en sus artículos ${ }^{22}$. Su análisis no es el objetivo de este estudio, pero vale la pena enumerarlos como elementos que también forman parte de la definición de "música nueva" que nos propone Falla. El primero es el abandono de las formas melódicas imperantes en los siglos XVII, XVIII y primeros dos tercios del XIX, estrechamente relacionadas con el aria operística. Falla, como se lee más arriba, proponía el uso de nuevas formas melódicas apoyadas en el recurso al modalismo. En segundo lugar, pensaba en las posibilidades que abrían las superposiciones tonales, aunque siempre respetando el predominio de una tonalidad, y la restitución de los modos antiguos y creación de otros nuevos. En tercer lugar, abogaba por la destrucción de la forma tradicional del desarrollo temático, "dando a la música una forma exterior que sea como consecuencia inmediata del sentimiento interno de la misma, y todo ello dentro de las grandes divisiones establecidas por el ritmo y la tonalidad"23. Además, dichos ritmos podían ser "obsesionantes". Estos principios fueron reformulados en 1933, a propósito de su crítica al concepto wagneriano de melodía infinita (definida como "sucesiones melódicas sin límites tonales"). Paso a citar: "Por lo que a la música concierne, pienso que, entre los pocos dogmas intangibles, ocupa un primer lugar aquel que exige la unión interna del ritmo con la tonalidad, y que sólo por la obediencia a este eterno principio puede adquirir el artificio sonoro potencia de estabilidad" ${ }^{24}$. En ese mismo texto, afirma perentoriamente que "toda la música" está contenida en los

20. Ibídem, pp. 76-77.

21. Manuel de Falla, "Falla y el romanticismo. Carta a Darío Pérez", en Escritos sobre música y músicos, op. cit., p. 131.

22. Cf., por ejemplo, Manuel de Falla, "Introducción a la música nueva", en Escritos sobre música y músicos, op. cit., pp. 30-43.

23. Ibídem, p. 42.

24. Manuel de Falla, "Notas sobre Ricardo Wagner en el cincuentenario de su muerte", en Escritos sobre música y músicos, op. cit., p. 140. 
siguientes dos principios naturales: en primer lugar, la forzosa determinación de los límites para captar el desarrollo en el tiempo y en el espacio de la música; y, en segundo lugar, la verdad fundamental de la escala natural acústica, plenamente sometidos al ritmo.

Añadiré, finalmente, que dichos medios expresivos, aun pudiendo ser "procedimientos puramente musicales" ${ }^{\prime 25}$, estaban, por un lado, dependientes del "medio ambiente", lo que, por un lado, justifica metonímicamente la posibilidad de que la música tuviera un carácter "racial" y "nacional", además de "individual". Por otro lado, dichos procedimientos tenían, como Jano, una historia con dos caras. Mirando hacia el pasado, "el presente musical vuelve a unirse, en cierto modo, con el pasado más remoto, con el principio natural de la música" ${ }^{26}$. Mirando hacia el futuro, "los nuevos compositores que aparezcan [...] seguirán los pasos de aquellos que han forzado la entrada del camino de verdad y libertad que conduce a la belleza pura, donde la música triunfa por sí misma, redimida al fin por el trabajo y hasta, en muchos casos, por el martirio de algunos hombres de buena voluntad"27. En su narrativa mística y triunfante, del esfuerzo por libertarse de determinados medios de expresión ("viejas rutinas") había nacido la música nueva: "la música libre de trabas y tutelas ajenas, que vive por sí y para sí y que aspira a realizar aquel ideal, que fue causa inconsciente de las primitivas manifestaciones del arte sonoro" ${ }^{28}$. En resumen, parece evidente que, por una parte, su concepción amplia de la evocación le permitía abolir límites entre la mente y la naturaleza y entre el presente y el pasado. Por otra parte, como ya he apuntado, la distinción entre evocación y medios de expresión implicaba, en su caso, la primacía fundamental de la música "pura". Esto es, el "arte mágico de la evocación" dependía de medios de expresión concretamente definidos mediante su caracterización puramente formal.

Como se ve, Falla nunca llegó a dar una definición del concepto. A partir de lo expuesto, sin embargo, se puede establecer esta proposición: la evocación es concebida por el compositor como función primordial de la música, en particular, aludiendo a las categorías analizadas en el estudio clásico de Alan P. Merrian ${ }^{29}$, de tipo expresivo (la evocación debe llevar aparejada la emoción), estético (está relacionada con determinados "medios de expresión" concebidos

25. La afirmación surge a propósito de Beethoven y Wagner, v. Manuel de Falla, "Introducción a la música nueva", en Escritos sobre música y músicos, op. cit., p. 38.

26. Ibídem, p. 36.

27. Ibídem, pp. 35-36.

28. Manuel de Falla, "Introducción a la música nueva", en Escritos sobre música y músicos, op. cit., p. 31.

29. Alan P. Merriam, "Usos y funciones", en Francisco Cruces Villalobos (ed.), Las culturas musicales: lecturas de etnomusicología, Madrid, Trotta, 2001, pp. 275-296 (publicado originalmente en inglés en The Anthropology of Music, 1964). 
desde una perspectiva formalista) y representación simbólica. Se relaciona, como acabo de adelantar, con un concepto expresivo del arte, por lo tanto, pero no tanto de ideas, como de sensaciones, emociones e impresiones, tal como parece deducirse de la siguiente afirmación: "La música no se hace, ni debe jamás hacerse, para que se comprenda, sino para que se sienta" ${ }^{\prime 30}$. Dicha evocación debe orientar la elección de los "medios de expresión", utilizados con "sinceridad", por el compositor.

\section{La impresión como premisa}

La importancia otorgada a la evocación sitúa a Falla, tal como a Debussy, en un contexto específico, creado por la preeminencia otorgada a la corporeización del mundo por parte del artista, una operación previa con doble sentido, sintetizada en la famosa formulación de Zola, según la cual "une oeuvre d'art est un coin de la création vu à travers un tempérament" ${ }^{\prime 31}$. El origen más plausible de esta idea, señalado en estudios sobre el impresionismo y el postimpresionismo como el de Richard Schiff, ya citado, puede encontrarse en los trabajos de Émile Littré sobre lo que él denominó fisiología psíquica ${ }^{32}$. Lo más relevante en la perspectiva de las artes es su reformulación del concepto de impresión percibida, entendida como la única manera posible para el sujeto de conocer el mundo exterior. Transformó la célebre máxima de Descartes, "pienso, luego existo", por la siguiente: "siento, luego pienso". Al atribuir la primacía a la impresión, es ésta la que garantiza el ser del sujeto humano sincronizando o armonizando, por así decirlo, lo externo y lo interno; el conocimiento objetivo y el conocimiento subjetivo; la impresión percibida y la impresión sentida; o, dicho de otra forma, la sensación y la emoción. Los artistas, como cualquier sujeto humano, siguiendo a Littré, sólo pueden conocer y expresar el mundo de esa manera, aunque, en esta época, se les reconociera una autoridad particular en la materia. Esta opera-

30. Manuel de Falla, "Prólogo a la Enciclopedia abreviada de música, de Joaquín Turina", en Escritos sobre música y músicos, op. cit., p. 53.

31. Se trata de un tópico omnipresente en la teoría del arte del modernismo, así como en las declaraciones y escritos de un número más que significativo de artistas. En lo que se refiere a Falla, si bien no ha sido analizado teóricamente, surge evidenciado de forma empírica en la importancia que la saturación sensorial producida por el paisaje tenía en su proceso creativo. V., a este respecto, Yvan Nommick (ed.), De torres, terrazas y jardines en la obra de Manuel de Falla. El jardín de Melisendra, Granada, Archivo Manuel de Falla, 1999; Antonio Gallego. "Noche, música y jardín: Sonidos y perfumes nocturnos en las lecturas de Manuel de Falla", en Alfredo Aracil (ed.), Música y jardines, Granada, Archivo Manuel de Falla, 2003, pp. 103-123; Francisco Baena y Yvan Nommick (eds.), Manuel Falla y la Alhambra. Catálogo de exposición, Granada, Patronato de la Alhambra y Generalife, 2005.

32. Me refiero a "De quelques points de physiologie psyquique", publicado en la revista $L a$ Philosophie positiviste en 1860 y reimpreso en La science au point de vue philosophique, especialmente pp. 306-327. 
ción teórica, en realidad, podía fundamentar cualquier tipo de apropiación del mundo exterior e introducía la sensación y la emoción en el centro, no sólo del arte, sino de la moral y la política.

Justo un año después, en 1861, Charles Baudelaire publicó, en la Revue Européene, su célebre artículo sobre Richard Wagner y Tannhäuser. Este ensayo seminal y su posible influencia en la crítica musical y en los compositores modernistas posteriores no ha sido suficientemente valorado en el ámbito de la musicología histórica. Me remito al artículo de Jann Pasler en el New Grove Dictionary en la medida en que desvela una cierta normalización de la comunidad académica: al centrarse en el término impresionismo y no en aquel del que se deriva, impresión, sitúa en los años 80 del siglo XIX los primeros usos documentados del mis$\mathrm{mo}^{33}$. Es más, en el mismo diccionario, en la entrada dedicada al poeta, Katherine Bergeron afirma que la teoría de las correspondencias que expone dicho artículo "puede que no transforme nuestra manera de entender el arte romántico", aunque ofrezca "una oportunidad notable para nosotros de reescuchar a Wagner a través de los oídos de uno de los oyentes más imaginativos del siglo XIX"34. Este afán por individualizar la escucha de Baudelaire, redunda en que no se presta suficiente atención al hecho de que el poeta, en su ensayo, utiliza el término impresión como si fuera del dominio de la comunidad artística, introduciendo la música wagneriana como "una de esas impresiones felices que todos los hombres imaginativos han conocido, a través del sueño cuando duermen". Es más, se refiere particularmente a la "impresión" que le produjo la audición del preludio de Lohengrin, y cuya retórica resulta llamativamente análoga a la usada por Falla para escribir sobre la Granada soñada por Debussy y sobre la impresión que la música que la evoca tiene en quien la escucha, que he transcrito en la sección anterior. Leamos directamente a Baudelaire, quien contrasta su "impresión" trayendo a colación descripciones de Wagner y Liszt del mismo fragmento, y que desarrolla sus argumentos de la siguiente forma:

Recuerdo que desde los primeros compases sentí una de esas impresiones dichosas que casi todos los hombres imaginativos han conocido, a través del sueño cuando duermen. Me sentí liberado de los lazos de la pesadez y recuperé en el recuerdo la extraordinaria voluptuosidad que circula por los lugares elevados (señalemos de pasada que no conocía el programa antes citado). A continuación me pinté involuntariamente el delicioso estado de un hombre presa de una ensoñación grandiosa en una soledad absoluta, pero

33. Jann Pasler, "Impressionism", en L. Macy (ed.), Grove Music Online, (Último acceso 1 de marzo de 2013), http://www.grovemusic.com.

34. "May not transform our understanding of Romantic art [aunque ofrezca] a remarkable opportunity for us to rehear Wagner through the ears of one of the century's most imaginative listeners." V. Katherine Bergeron, "Baudelaire, Charles", en L. Macy (ed.), Grove Music Online, (Último acceso 1 de marzo de 2013), http://www.grovemusic.com. 
una soledad con un inmenso horizonte y una amplia luz difusa; la inmensidad sin más decoración que ella misma. Pronto experimenté la sensación de una claridad más viva, de una intensidad luminosa que crecía con tal rapidez que los matices ofrecidos por el diccionario no bastarían para expresar aquel incremento de ardor y blancura que se reproducía sin cesar. Entonces vislumbré plenamente la idea de un alma moviéndose en un medio luminoso, de un éxtasis hecho de voluptuosidad y conocimiento, que se cernía por encima y muy lejos del mundo natural ${ }^{35}$.

En ese mismo ensayo, se consagra la idea de que hay una "manera lírica de sentir" sobre la que se fundamenta la posibilidad de percibir las correspondencias o analogías, no sólo entre las artes, sino, añado, entre impresiones percibidas. La contemporaneidad de la retórica usada por Baudelaire con la psicología de su tiempo, no sólo lo relaciona con Littré, sino con otro de los autores más influyentes en esta materia: Hippolyte Adolphe Taine. Parece conveniente en este punto fijar qué es lo que en la segunda mitad del siglo XIX se entendía por impresión y, para ello, me serviré del ensayo De l'intelligence, publicado por Taine en 1870. Sus dos volúmenes son una referencia incontestable en el ámbito de la psicología, pero también lo son en el ámbito de las artes, incluyendo la música. Además, ese ensayo constituye el fundamento de Philosophie de l'art (1893). Su reputación posterior, debida en parte a una aplicación muy simplificada de su explicación psico-sociológica y determinista de la obra de arte, no debe impedirnos una relectura de estos textos.

Según Taine, pensamos a través de signos, o sea, mediante "ideas representativas", asociadas, bien con sensaciones, bien con imágenes. Ambas, sensaciones e imágenes, median entre el objeto y el sujeto, pero son sólo posibles en el sujeto. La impresión es el fundamento de la percepción unida a la emoción, es decir, a su reconocimiento asociado: cualquier estímulo puede ser sentido o,

35. "Je me souviens que, dès les premières mesures, je subis une de ces impressions heureuses que presque tous les hommes imaginatifs ont connues, par le rêve, dans le sommeil. Je me sentis délivré des liens de la pesanteur, et je retrouvai par le souvenir l'extraordinaire volupté qui circule dans les lieux hauts (notons en passant que je ne connaissais pas le programme cité tout à l'heure). Ensuite je me peignis involontairement l'état délicieux d'un homme en proie à une grande rêverie dans une solitude absolue, mais une solitude avec un immense horizon et une large lumière diffuse; l'immensité sans autre décor qu'elle-même. Bientôt j'éprouvai la sensation d'une clarté plus vive, d'une intensité de lumière croissant avec une telle rapidité, que les nuances fournies par le dictionnaire ne suffiraient pas à exprimer ce surcroît toujours renaissant d'ardeur et de blancheur. Alors je conçus pleinement l'idée d'une âme se mouvant dans un milieu lumineux, d'une extase faite de volupté et de connaissance, et planant au-dessus et bien loin du monde naturel." Charles Baudelaire, "Richard Wagner et Tannhäuser à Paris" (1861), en Oeuvres completes, vol. 2, texte établi, presenté et annoté par Claude Pichois, Paris, Gallimard, 1975, pp. 784-785. Las cursivas son del autor. Traducción de Carlos Wert, extraída de El arte romántico, Charles Baudelaire, Madrid, Felmar, 1977. 
dicho de otra forma, traducido en emociones. Es más, dichos estímulos no se reducen a sensaciones. Taine iguala toda percepción a formas de alucinación, aunque distinga entre alucinaciones "verdaderas" y las que se producen en estados como el sueño o la hipnosis. No es difícil establecer una relación entre esta idea y el extracto de la crítica de Baudelaire que he transcrito más arriba. Lo interesante, como he adelantado, es que, Taine fundamenta que, al crear imágenes, el sujeto no necesita estímulos exteriores, es decir, para percibirlas, puede prescindir de las sensaciones. Para Taine, la imagen es el tipo de signo que no se fundamenta necesariamente en la experiencia externa, esto es, el signo evocado. Las imágenes pueden ser reviviscencias de las sensaciones pero, como digo, no son únicamente dependientes de éstas. La imaginación es precisamente la facultad que se invoca aquí, entendida como capacidad de evocar imágenes incluso en ausencia de objetos del mundo físico que las provoquen.

El filósofo dio un paso más allá, al adentrarse en la filosofía del arte y al definir al artista, en ese contexto, como un tipo especial, capaz de percibir, con más delicadeza y rapidez que los demás cualquier sensación. Es más, según su razonamiento, el artista se define precisamente por la capacidad de sintonizar, hacer durar en el tiempo y explorar la "sensación original" o "sensación espontánea" producida por un determinado objeto, o, con otras palabras, de vibrar con é ${ }^{36}$. En un movimiento subsiguiente, que también se desarrolla en la primera parte de De l'intelligence, Taine establece que la relación entre dichas imágenes y el exterior se realiza mediante el lenguaje: éste no sería, sino un sustituto de las imágenes, el medio a través del cual las expresamos. Por analogía, el arte no es sino una forma de expresar imágenes mediante "medios artísticos", en particular, mediante una estructura o "relaciones entre las partes" plasmadas en obras concretas $^{37}$. En su Philosophie de l'art, Taine revisita los conceptos de sensación e imagen, para proponer que el arte moderno se caracteriza por una relación complicada y tortuosa con las imágenes, que ya no se establece sobre la base de la espontaneidad, sino de un esfuerzo creativo suplementar. Citando a Paolo Tortonese: "Demasiado alejados de la imagen por la fuerza intelectualizante de la civilización, intentan reconquistarla mediante un supremo esfuerzo de la voluntad, lo que altera finalmente su relación con el mundo exterior, haciendo primar la imagen artificial sobre la sensación" ${ }^{\prime \prime 3}$. Es posible que esta constatación de la "decadencia" del arte moderno esté en el origen de la valoración de la sinceri-

36. Hyppolite Taine, De l'intelligence, Tome Premier, Paris, Librairie Hachette, 1870, pp. 44-45. 37. Ibídem, p. 46.

38. “Trop éloignés de l'image par la force intellectualisante de la civilisation, ils cherchent à la reconquerir par un suprême effort de la volonté, ce qui altère finalmenet chez eux le rapport avec le monde extérieur, faisant primer l'image artificielle sur la sensation." V. Paolo Tortonese, «Taine, art et hallucination», en Matthias Waschek (ed.), Relire Taine, Paris, École Nationale Supérieure des Beaux-Arts, 2001, p. 76. 
dad y la espontaneidad como cualidades positivas de la obra artística y del propio artista, así como en la obsesión casi febril, patente en el caso de Falla, por revivir con la música lo que él denomina como el espíritu del arte primitivo.

\section{El arte mágico de evocar}

Desde el punto de vista de la psicología, la evocación es un proceso simbólico asociado a la memoria. Supone traer a la consciencia determinada información, especialmente bajo la forma de imágenes mentales, sensaciones e, incluso, emociones. Las teorías de Littré y Taine, como he mostrado, actualizaron la tendencia idealista surgida en la reflexión kantiana, desligando, al menos en teoría, las imágenes producidas por el cerebro humano de la realidad. Henri Bergson es el autor que dio un paso adelante en la misma senda al defender la diferencia irreductible entre el cuerpo y la consciencia. Essai sur les données immédiates de la conscience (1889) y, sobre todo, Matière et mémoire (1896) son los dos trabajos en los que reflexionó sobre el asunto. En el segundo, estableció el principio de que la consciencia (o el alma o espíritu) siempre transcurría en el tiempo pasado. La evocación, en ese contexto, se destacaba como una actividad mental superior, propia de lo que Bergson llama memoria imaginativa para distinguirla de la memoria repetitiva, que es definidora de la humanidad:

Para evocar el pasado en forma de imagen es preciso poder abstraerse de la acción presente, es preciso saber conceder importancia a lo inútil, es preciso querer soñar. Aun el pasado al que así nos remontamos es escurridizo, siempre está a punto de escapársenos, como si esta memoria regresiva fuese contrariada por la otra memoria, más natural y cuyo movimiento hacia delante nos impele a actuar y a vivir ${ }^{39}$.

Releyendo a Falla, de hecho, parece que, en su manera de entender la evocación, la concibe como un acto de naturaleza doble, con elementos tanto espontáneos como voluntarios. La "evocación de sentimientos, de seres y aún de lugares" que, como ya se ha referido, debía ser, en su opinión, el propósito fundamental de la música nueva, está, por lo tanto, dependiente de la facultad voluntaria del artista para crear y relacionar imágenes, al tiempo que, idealmente, debían orientarse por un principio de naturalidad y espontaneidad. Ade-

39. "Pour évoquer le passé sous forme d'image, il faut pouvoir s'abstraire de l'action présente, il faut savoir attacher du prix à l'inutile, il faut vouloir rêver. L'homme seul est peutêtre capable d'un effort de ce genre. Encore le passé où nous remontons ainsi est-il glissant, toujours sur le point de nous échapper, comme si cette mémoire régressive était contrariée par I'autre mémoire, plus naturelle, dont le mouvement en avant nous porte à agir et à vivre." V. Henri Bergson, Matière et mémoire. Essai sur la relation du corps à l'esprit (1896), Paris, Félix Alcan, 1903, 3a ed. por donde cito, pp. 79-80. Traducción de José Antonio Miguez, extraída, tal como las siguientes, de Henri Bergson, Obras escogidas, Madrid, Aguilar, 1963. 
más, dentro de los actos voluntarios, y aún así dependientes del "medio", implicados en la creación artística se pueden incluir los medios de expresión. Apoyándonos de nuevo en Bergson, cabe destacar la posibilidad teórica de que ese proceso se concibiese como una especie de continuo, en el que intervenían lo que el filósofo denomina recuerdo puro, recuerdo-imagen y percepción, ninguno de los cuales se da aisladamente ${ }^{40}$. Sin embargo, a pesar de ello, el mismo autor distingue claramente entre imaginación y recuerdo:

Imaginar no es recordarse. Sin duda, un recuerdo, a medida que se actualiza, tiende a vivir en una imagen; pero la proposición recíproca no es verdad, y la imagen pura y simple no me transportará al pasado si yo no he ido ya, en efecto, a buscarla en el pasado, siguiendo así el progreso continuo que la ha llevado de la oscuridad a la luz ${ }^{41}$.

Curiosamente, el filósofo Vladimir Jankélévich, quien ha reflexionado en torno a los problemas que estoy abordando y una de cuyas referencias fundamentales es, precisamente, el pensamiento de Bergson, no parece haber dado importancia a esta diferencia ${ }^{42}$. En su conocido ensayo, La musique et l'ineffable, en el que discute, entre otras, obras de Falla, dedica una sección a la cuestión de la evocación, estableciéndola como resultado de una transposición alusiva, de la analogía de una analogía, y situándola en las "brumas del recuerdo y en la irrealidad del sueño" ${ }^{43}$. Esta localización se afirma a propósito de "Evocación", la primera de las doce "impresiones" que forman Iberia, de Isaac Albéniz, pero se relaciona con obras de otros compositores que también estaban estrechamente relacionados con Falla, como Gabriel Fauré, Paul Dukas o el ya mencionado Claude Debussy, entre otros. No obstante, en realidad, no nos dice mucho más acerca de su significado, más allá de la apología de la no referencialidad de la música, es decir, de su definición negativa como no-descripción. El trabajo de

40. Ibídem, p. 143.

41. "Imaginer n'est pas se souvenir. Sans doute un souvenir, à mesure qu'il s'actualise, tend à vivre dans une image ; mais la réciproque n'est pas vraie, et l'image pure et simple ne me reportera au passé que si c'est en effet dans le passé que je suis allé la chercher, suivant ainsi le progrès continu qui l'a amenée de l'obscurité à la lumière." Ibídem, p. 146. La cursiva es del autor.

42. De hecho, esta reflexión tampoco aparece en los trabajos que estudian específicamente la evocación en una perspectiva poética. Queda, por supuesto, fuera del propósito de este artículo discutir el concepto de evocación el ámbito de la teoría literaria o en el de las diferentes disciplinas que estudian los procesos de construcción de sentido. V., no obstante, por ejemplo, In-Ryeong Choi-Diel, Évocation et cognition. Reflets dans l'eau, Saint Dennis, Presses Universitaires de Vincennes, 2001, fundamentado sobre los trabajos de Marc Dominicy. Grosso modo, y en reflejo de las fuentes primarias sobre las que se basan, la evocación es el término utilizado en estos trabajos para designar una forma específica de significación, propia del arte, definida negativamente frente a la descripción y que subraya la no referencialidad del "signo" artístico.

43. Vladimir Jankélévitch, La música y lo inefable, Barcelona, Alpha Decay, 2005, p. 90. La primera edición en francés es de 1983. 
la memoria basado en el establecimiento de parecidos entre percepciones o imágenes es, de hecho, suficiente justificación para adoptar ese punto de vista "de conjunto", reivindicado por Jankélévich como modo de percepción musical. La confusión puede remontarse al propio Baudelaire quien, como se ha visto en la cita antes transcrita, identifica el ensueño con el recuerdo al describir la impresión que le produjo la audición de Tannhäuser desde los primeros compases.

El hecho de que Falla incluyera en su afirmación el adjetivo "mágico" -en la metáfora según la cual el "espíritu primitivo" de la música era el de ser un "arte mágico de evocación", a la que ahora retornamos- apunta hacia otro posible contexto referencial, que es el de las corrientes ocultistas, tan de moda en París hacia 1900. No estoy afirmando que Falla fuese espiritista, como tampoco afirmo que fuese un atento lector de Littré, Taine y Bergson. Lo que quiero mostrar es que el uso que hace de la palabra evocación requiere una definición que se encuentra, en rigor, no en los estudios de psicología, sino en otro lugar. Evocar es, literalmente, la acción de llamar o hacer aparecer espíritus y era una práctica -prohibida en el Antiguo Testamento y también por la Iglesia Católicatradicionalmente asociada a la magia que, además, se percibía exteriormente como uno de los elementos más importantes del ocultismo. Victor Blanchard, en la conferencia que pronunció en el Congreso Masón y Espiritualista organizado en París en 1908, lo dejó bien claro: "En el Mundo profano, se cree generalmente que el Ocultismo no se ocupa más que de la evocación mágica de los espíritus de la Naturaleza o de los humanos ya muertos" ${ }^{\prime 4}$.

Es decir, el psicologismo que fundamenta la manera falliana de concebir la música acaba resolviendo en una especie de fantasía: a la realidad "real", se impone una realidad simbólica supuestamente más profunda y, por supuesto, atemporal, además de condicionada por el medio, la raza y el lugar, según la formulación de Taine retomada a su manera por Falla. En última instancia, se podría pensar que la magia sincrética de la música es sólo percibida por los creyentes. Sin embargo, de la misma manera, su estética se resuelve en una semanticidad que sólo es contradictoria en apariencia, y que también está patente, por ejemplo, en Mallarmé: la función evocativa de la música, considerada como siendo fundamental, y que resume la posibilidad de establecer analogías entre imágenes o, quizá, "alucinaciones" en el sentido de Baudelaire y de Taine, se neutraliza con una concepción formalista de los medios expresivos y de la propia obra musical. En realidad, la naturaleza de las relaciones específicas de

44. "Dans le Monde profane, on se figure généralement que l'Occultisme ne s'occupe que de l'évocation magique des esprits de la Nature ou de ceux des humains décédés." V. Victor Blanchard, "L'occultisme", conferencia inaugural del Congreso Espiritualista celebrado en París en 1908. Las actas completas fueron editadas por la Librairie Hermetique en 1910. Cito, sin embargo, a partir de la reproducción disponible en el sitio web "La Belle Époque de l'élan capitaliste", (último acceso 1 de marzo de 2013), http://voie-lactee.fr/la-belle-epoque-de-I-elan-capitaliste. 
carácter semántico establecidas a partir de la música se deriva, precisamente, de la especificidad de los medios expresivos de los que se sirve y que la diferencian, sólo en cuanto medios de expresión, por ejemplo, del lenguaje verbal. O sea, el lenguaje verbal y musical pueden desencadenar un proceso de semantización análogo en cuanto no se reduce a la relación de sentido establecida entre un signo y su referente o a un modo de significación conceptual y discreto. Un proyecto ineludible será el de verificar de qué forma este concepto de semántica musical que parece ser subyacente al pensamiento de Falla se actualiza en obras musicales concretas.

Concluyendo, para Manuel de Falla, la "música nueva" se proponía como un conjunto de elementos, técnicamente analizables como impresión/sensación al tiempo que unificados bajo la impresión/emoción, que imponían un concepto semántico $-y$, por supuesto, impresionista- de música definido por sus funciones, de las cuales, la principal, era la de evocar "sentimientos, seres y lugares". Independientemente de su origen, lo importante es que la metáfora de la evocación subraya, por un lado, el carácter no directa y unívocamente referencial de la música como proceso de representación simbólica y, por otro, el rechazo de que su expresividad fuera puramente subjetiva o incomunicable. Está, de hecho, latente en la elección de la "evocación" como figura una desconfianza hacia la hegemonía expresiva del yo y hacia su papel irreducible como modo de estructurar la relación del sujeto con la realidad. La pureza a la que aspiraba Falla también se relaciona con esta cuestión: su formalismo se ve reforzado por su aversión a las expansiones "egoístas" del yo que se manifiestan en alguna facción del romanticismo. Siendo una concepción del arte que es, por así decirlo, hija de su época, la disciplina con la que Falla identificó esta definición de música nueva con su propio proceso creativo es quizá particularmente específico de su caso. Resulta llamativa la resonancia que adquiere, bajo esta perspectiva, la declaración de Taine acerca de la impotencia de los artistas modernos para reatar la relación espontánea con la creación de imágenes que tenían los primitivos. Parece aludir crudamente al largo y a veces tortuoso proceso creativo falliano, documentado en diversas fuentes. 